\title{
Domination of Organizational Culture Characteristics Value towards the Improvement of Employee Performance at a Company in Banten Province
}

\author{
Santi Riana Dewi \\ University of Serang Raya \\ santirianadewi@yahoo.co.id
}

\begin{abstract}
This research aims to determine the dominance of the organizational culture characteristics values toward the improvement of employee performance in at a company in Banten, so as to encourage accelerated achievement of employee's superior performance. The method used is a survey with a causal approach, will be analyzed by using correlation model. The data used are usually scaled interval or ratios. Data collection techniques used are questionnaires, while the data analysis techniques used are descriptive data analysis and inferencing statistical data using linear regression test, t-test, and determination analysis. Variables to be studied are the characteristics of organizational culture and employee performance. With the result of the research, it is known that the dominance influence of the characteristics values of organizational culture on employee performance, then the empowerment of organizational culture values is needed.
\end{abstract}

Keywords: organizational culture characteristics, dominance, improvement, and performance.

\section{INTRODUCTION}

The industry in Banten prepares to implement ten national initiatives covering the flow of material flows, redesigning industrial zones, improving the quality of human resources, empowering SMEs, adopting technological investment incentives, creating innovative ecosystems, attracting foreign investment, harmonizing rules and policies, building infrastructure and accommodation of sustainability standards. That is, answering the problem then the company must make continuous changes in preparing to win disruption by improving the quality of human resources in the company that is to improve employee performance. As stakeholders, industry actors have a major role to produce products with quantity and quality in the most effective time possible in accordance with consumer expectations.

There are several factors that will affect the quality of employee performance, among others, is the characteristics of organizational culture. The problem facing the company at this time is to find the dominant factors that will be able to improve the quality of employee performance. Based on the problem identification there are several things that still need to be improved such as empowering organizational culture, training, coaching, spiritual intelligence, sense of belonging, and servent leadership. As for this research focused on the dominance influence of characteristic of organizational culture toward improvement of employee performance quality. The problem is not known whether or not there is influence of organizational characteristic to the improvement of employee performance and how big its dominance at company in Banten province at this time, with hypothesis there is influence of organizational culture characteristic to the improvement of employee performance.

Here are some research results in the journal that refers to the influence of organizational culture characteristics to the improvement of employee performance.The results obtained from this part of the study are mixed. The strength of cultural values was found to be correlated with the organizational performance of firms in a few cases. For example, Performance management is a process of delivering sustained success to organizations by improving capabilities of individuals and teams. Organizational culture as a significant contextual factor in performance management is scarcely studied. The aim of this study is to expand the base of knowledge and empirically test the relationship between components of organizational culture and performance management practices. Statistical results show that involvement is highly correlated with consistency and adaptability. Similarly, other dimensions of organizational culture have significantly positive relationship with the performance management practices[1]. Findings from path analysis showed that the achievement and adaptive cultural orientations had adirect effect on performance. A research limitation is that the causal direction of the relations between the predictors and the criteria has been partially established by controlling for the effect of past performance on the perceptions of organizational culture and leadership[2].

The results of the current study indicate that two forms of culture (bureaucratic and community) are not directly related to performance. Interestingly, both 
bureaucratic and community cultures are each characterized by an emphasis on integration, internal cohesiveness, and the establishment of uniformity (that is creating a strong culture). In this sense, in the case of internally oriented cultures, little evidence is found to support claims of a link between cultural strength and performance. Hence, while the results indicate that the two internally oriented cultures are weakly and indirectly linked with performance [3], the total effects of such cultures on performance, are such that significant managerial attention to internal maintenance appears unproductive or even damaging. Interestingly, that which is distinctive about both competitive and innovative cultures is the emphasis each places on competitive external positioning and responsiveness. These findings are broadly consistent with a range of studies which suggest that externally oriented organizational cultures are positively linked with performance [4].Based on several results from the research that has been described above it can be concluded that there is an influence between characteristics of organizational culture to the improvement of employee performance.

The following will be presented some concepts about the characteristics of organizational culture among others as follows. There are seven main characteristics of organizational culture: (1) innovation and risk-taking, i.e. the extent to which employees are encouraged to innovate and dare to take risks; (2) attention to details, i.e. the extent to which employees show carefulness, analysis, and attention to details; (3) outcome orientation to what extent management focuses on results rather than on the techniques and processes used to achieve those outcomes; (4) people's orientation: the extent to which management decisions account for the effect on people in the organization; (5) team orientation: the extent to which work activities are organized around teams, not individual approaches; (6) Aggressiveness: the extent to which people in the organization are aggressive and competitive rather than casual; (7) stability: the extent to which organizational activities emphasize the status quo rather than growth [5].Organizational Culture manifested in beliefs and assumptions, values, attitudes and behaviors of its members is a valuable source of firm's competitive advantage [6] since it shapes organizational procedures, unifies organizational capabilities into a cohesive whole, provides solutions to the problems faced by the organization, and, thereby, hindering or facilitating the organization's achievement of its goals [7].

To develop a performance measurement instrument, competency analysis is required. The technique may use performance appraisal or other means, depending on the nature of the performance to be measured and the measurement strategy deemed appropriate to the company's vision, mission and objectives. The factors that become elements of employee performance appraisal are achievement motivation, have an impact on results, analytical ability, strategic thinking, ability to innovate, have creative thinking, able to take decisions, business perspective, group management, leadership, interpersonal relationships, communication skills, adaptability, able to handle change, able to face pressure and ability to make plans [8]. There are a number of performance indicators as follows: 1. Knowledge of work and profession 2 . Sensitivity to customer, 3.Communication, 4. Interpersonal skills, 5. Group work, 6.Initiative, 7. Analytic, 8. Productivity, 9. Quality, 10. Supervision, 11. Leadership[9].Based on the description of some concepts about organizational culture in which there are several organizational characteristics, it can be taken to the conclusion that the characteristics of the organization is one factor that can provide a positive impact for performance improvement. Characteristics of the organization is the values and rules contained in the organisaasi either in the depth or not, so that in the implementation that will continuously become the hallmark of the organization.

\section{METHOD}

Respondents in this study were 68 employees from a manufacturing company in Merak Banten from various parts. The results of data recalculation along with the value of the organizational culture characteristics and employee performance will be used as preliminary data for the research analysis. The result of descriptive analysis is done to give a brief description about respondent profile, organizational culture characteristics, and employee performance in company. Respondent's profile will be explained by sex, age, education level and years of service. In this study used a simple linear regression analysis. This analysis to know the magnitude of influence between the variable characteristics of organizational culture to performance variables. In addition, simple correlation analysis is used to find out the variables are positive or negative and to predict the value of the dependent variable if the value of the independent variable increases or decreases. Determination analysis $\left(\mathrm{R}^{2}\right)$ is done to know the dominance percentage contribution of influence of independent variable to dependent variable. The data used are usually scaled intervals or ratios. To minimize the likelihood of manual error counting with mathematical operational equations, then used instrument software. According to [10], the guidelines for interpretation of correlation coefficients are as follows: $0.00-0.199=$ very low, $0.20-0.399=$ low, $0.40-0.599$ = medium, $0.60-0.799=$ strong $, 0,80-1,000=$ very strong. In addition, partial regression coefficient test $(\mathrm{t}-$ test) is used to find out whether in the regression model of independent variables partially significant effect on the dependent variable.

\section{RESULT}

This study uses primary and secondary data. Primary data is in the form of the result of questionnaires distributed and has been filled by company employees. Indicators of organizational characteristic variables include responsibility, innovation, risk taking, accuracy, work outcomes, cooperation, aggressiveness, stability of activities, communication, and work rewards. 
Meanwhile, the indicators of performance include skills, work discipline, customer satisfaction, productivity, quality standards, efeisiensi use of materials, work environment, responsibility, and team work. The secondary data used data obtained from the company in the form of reports that become the reference in identifying the problem

The requirements test undertaken in this study is the validity and reliabilityquestionnaire test. In the statistical program of testing techniques conducted by researchers is the validity test Corrected Item - Total Correlation. As for the reliability test used Cronbach's Alpha technique. Based on the results that can be seen in Corrected Item Total Correlation will get correlation value of this value compared with $r$ table value with significance of 0.05 with 2 side test and the number $\mathrm{n}=68$ obtained $\mathrm{r}$ table $=$ 0.239 , all statements value more than 0.239 then stated all the instrument is valid. As for the reliability test used is the Cronbach Alpha method. From the above analysis we get the Alpha value of 0.785 whilethe value obtained is more than 0.600 it can be concluded that all the items of the research instrument are declared reliable. Hypothesis testing on the influence of organizational culturecharacteristics (X) on employee performance improvement(Y) is done by correlation analysis. The results of correlation analysis in the table show that the variable characteristics of organizational culture with performance is 0.544 , it means having a moderate relationship. The significance tes with the correlation quantity using t-test obtains a probability value of 0.000 . This probability value is lower than the specified significance value of 0.05 . Thus can be interpreted between the variable characteristics of organizational culture with employee performance variables there is a very significant relationship.From t-test the results seen thet the value of $t$ calculated $=5.268>\mathrm{t}$ table $=1.997$, it means that the influence of organizational culture characteristics towardsemployee performance improvement is significant. Further more the result of domination influence of organizational culture characteristics value towards the improvement of employeeperformance will be shown in the table1 .

Table 1. Determination Coefficient.

\begin{tabular}{rrrrr}
\hline Model & $\mathrm{R}$ & $\mathrm{R}$ Square & $\begin{array}{c}\text { Adjusted R } \\
\text { Square }\end{array}$ & $\begin{array}{c}\text { Std Error of } \\
\text { the Estimate }\end{array}$ \\
\hline 1 & .544 & .296 & .285 & 2.973 \\
\hline
\end{tabular}

Based on the results of determination coefficient analysis obtained $\mathrm{r}^{2}=0.296$, meaning that the influence or contribution values of the characteristics of organizational culture to employee performance improvement is $29.6 \%$, while the rest is influenced by other variables. This means empowering the characteristics of organizational culture that employees follow will lead to improved employee performance and vice versa. With the reduction of empowerment of employee organizational culture characteristics will lead to decreased employee performance.

\section{CONCLUSION}

Based on the results of data processing and analysis of research results on the influence of organizational culture characteristics to the improvement of employee performance at a company in Merak Banten can be concluded as follows. The influence of descriptive test of organizational culture characteristic value toward employee performance is moderate with empowering values of characteristic of organizational culture from employees as a whole is obtained percentage (54.4\%), by doing hypothesis test hence can be seen that relation between characteristic of organizational culture values to performance being strong then it can be concluded that by empowering the values of the characteristics of organizational culture in employees does contribute to the improvement of employee performance. Based on the statistical test on the value of the characteristics of organizational culture found in the company, by considering the result of the hypothesis test on the influence of the organizational culture characteristics on the performance improvement, it can be concluded that the characteristics of organizational culture give positive influence to the improvement of employee performance in at a company in Merak, Banten. This means that with the empowerment of values of organizational culture characteristics, the contribution of $29.9 \%$ to the improvement of employee performance in the company of all variables that influence the improvement of employee performance. Based on these findings, the company is expected to increase the empowerment of organizational culture characteristic values in the future to improve the quality of human resources through the improvement of employee performance.

\section{REFERENCES}

[1] M. Shakil Ahmad, "Impact of Organizational Culture on Performance Management Practices in Pakistan.," Business Inteligence Journal. 2012.

[2] Athena Xenikou, "Organizational Culture and transformational Leadership as Predictor of Business Unit Performance.," Journal of Managerial Psychology. 2006.

[3] Emanuel Ogbonna and Lloyd C. Harris, "Leadership Style, Organizational Culture and Performance.," The International of Human Resource Management. 2000.

[4] Greenley, "Market orientation and Company Performance.," British Journal of management. 1995.

[5] Robbins, Organizational Behavior. 2009.

[6] Hall,"A Framework of Conducting research and Social Realities,." Strategic Management Journal.1993.

[7] Yilmaz, "Organizational Culture and Firm Effectiveness,." Journal of World Business. 2008.

[8] M. Faisal Amir, Performance Evaluation. 2008

[9] Michael Amstrong, Performance Management. 1998. 
[10] Sugiyono, Metode Penelitian Bisnis. 2007. 